\title{
Changes in microflora in dental plaque from cancer patients undergoing chemotherapy and the relationship of these changes with mucositis: A pilot study
}

\author{
Iole Vozza $^{1}$, Vito Caldarazzo ${ }^{2}$, Livia Ottolenghi ${ }^{3}$
}

${ }^{1}$ DDS, PhD Department of Oral and Maxillo-facial Sciences, Sapienza University of Rome

${ }^{2}$ MD, DDS Department of Oral and Maxillo-facial Sciences, Sapienza University of Rome

${ }^{3}$ DDS Department of Oral and Maxillo-facial Sciences, Sapienza University of Rome

Correspondence:

Oral and Maxillo-facial Sciences Department

Sapienza University of Rome

Via Caserta 6, 00161 Rome, Italy

iole.vozza@uniroma1.it

\author{
Vozza I, Caldarazzo V, Ottolenghi L. Changes in microflora in dental \\ plaque from cancer patients undergoing chemotherapy and the relation- \\ ship of these changes with mucositis: A pilot study. Med Oral Patol Oral \\ Cir Bucal. 2015 May 1;20 (3):e259-66. \\ http://www.medicinaoral.com/medoralfree01/v20i3/medoralv20i3p259.pdf \\ Article Number: $19934 \quad$ http://www.medicinaoral.com \\ (C) Medicina Oral S. L. C.I.F. B 96689336 - pISSN 1698-4447 - eISSN: 1698-6946 \\ eMail: medicina@medicinaoral.com \\ Indexed in: \\ Science Citation Index Expanded \\ Journal Citation Reports \\ Index Medicus, MEDLINE, PubMed \\ Scopus, Embase and Emcare \\ Indice Médico Español
}

\begin{abstract}
Background: To assess changes in oral microflora in dental plaque from cancer patients within 7 days of the first course of chemotherapy, and the relationship of the changes with mucositis.

Material and Methods: Thirty cancer patients, divided into a test group undergoing chemotherapy and a control group no undergoing chemotherapy, were enrolled in this pilot study. Oral microflora were cultured from three samples of dental plaque at t0 (before chemotherapy), t1 (1 day after chemotherapy) and t2 (7 days after chemotherapy). Single and crossed descriptive analyses were used to establish prevalence, and the $\chi^{2}$ test was used to establish the statistical significance of the differences observed in distributions (significance level: $P<0.05$ ).

Results: In most patients (57\%), oral microflora consisted mainly of Gram-positive cocci, while the remaining $43 \%$ of the bacterial flora also had periodontal-pathogenic species. No Porphyromonas gingivalis appeared in the test group. Actinobacillus was the least frequently found bacterium among periodontal pathogens in the test group, while Fusobacterium nucleatum was the most frequently found. No significant differences were found in quantitative bacterial changes between $\mathrm{t} 0, \mathrm{t} 1$ and $\mathrm{t} 2$ in either the test or control groups, or between the two groups. According to World Health Organization scores, oral mucositis developed in 10 patients $(66.6 \%)$ in the test group. Conclusions: The results of this pilot study indicate that there were no changes in microflora in dental plaque in cancer patients within 7 days of the first course of chemotherapy. No correlations between oral mucositis and specific microorganisms were assessed.
\end{abstract}

Key words: Oral microflora, dental plaque, cancer patients, chemotherapy. 


\section{Introduction}

The human oral cavity is inhabited by upwards of 500 species of bacteria (1), most of which are harmless commensal organisms. Others, however, are pathogenic and are involved in the development of dental caries, periodontal diseases, and acute or chronic infections.

Cytotoxic chemotherapy compromises the oral defense mechanisms, either by direct mucosal damage or by neutropenia, potentially causing an overall shift in oral microflora. In patients undergoing chemotherapy, there is an increase in the number and proportion of some bacteria associated with periodontal diseases (Actinobacillus actinomycetemcomitans, Porphyromonas gingivalis and Fusobacterium nucleatum) (2-4), along with a diminished effectiveness of immune defense against infection (5). Mucositis is an oral complication that affects $30-40 \%$ of patients receiving chemotherapy and radiotherapy and $80 \%$ of those undergoing hematopoietic stem cell transplantation. It is a multifactorial disease defined as epithelial thinning associated with intense erythema, ulceration, pain, bleeding and increased risk of infection (6). The cytotoxic effects of anticancer drugs against highturnover tissues such as the oral epithelium, and the local effects of radiation on the oral mucosa are responsible for this event, which compromises quality of life and may interfere with management of the disease. Mucositis typically appears between 7 and 14 days after the initiation of chemotherapy, and is usually preceded by a subjective complaint of soreness or a burning sensation. Drugs most likely to cause mucositis include doxorubicin, bleomycin, fluorouracil, and methotrexate (7).

It is thought that the incidence and severity of cancerchemotherapy-associated mucositis is caused in part by changes in the oral bacterial microflora. Oral microorganisms are believed to be involved in the ulceration phase, where they probably intensify the inflammatory process and aggravate or promote the formation of ulcers (8). However, until now, it has been unclear whether there is an association between periodontal pathogens and mucositis (2).

Given the significant impact of oral mucositis on quality of life, it is essential to try to prevent it by all means possible. Currently, there are several treatments, but none of them has been validated in definitively (9). The aim of this pilot study was to assess changes in oral microflora in dental plaque in cancer patients within 7 days from the first course of chemotherapy, and their relationship with mucositis.

\section{Material and Methods}

\section{- Patients}

We enrolled 30 patients (16 men and 14 women, aged $32-59$ years) with solid malignancy. who had no previous adjuvant radiotherapy or recent antimicrobial or antiviral treatment. The primary, stage II, squamocellular cancer was located in the lungs ( 5 men and 1 woman), colonrectum ( 8 men and 5 women patients), prostate ( 3 men) and breast ( 8 women). The study was conducted at the Oncology Unit, Fiorini Hospital, Terracina, Italy. The study conformed to the Helsinki Declaration and the study was approved by the Medical Ethical Committee of Sapienza University of Rome. All patients gave their written informed consent. The patients were divided in two groups of 15: the test group consisted of patients undergoing a first course of chemotherapy with docetaxel or 5-fluorouracil and oxaliplatin; the control group consisted of patients not undergoing chemotherapy because of the stage of their disease and because they did not have adequate numbers of platelets and leukocytes (Table 1).

- Microbial analysis

Oral mucositis was scored according to World Health Organization (WHO) criteria (10) at eight nonkeratinized anatomical sites (labial and buccal mucosa, lateral and ventral tongue, floor of mouth, and soft palate) by one trained dentist (V.C.). Oral microflora were cultured from plaque specimens. All patients were sampled at time zero (t0) (immediately before chemotherapy), and on t1 ( 1 day after infusion) and $\mathrm{t} 2$ (7 days after infusion). Control subjects were sampled on equivalent dates. Sampling was done at the same time of day, approximately $2 \mathrm{~h}$ after breakfast. For each individual, the supragingival plaque of the right lower premolars was collected with a sterile swab. All specimens were processed within the following $4 \mathrm{~h}$. Following serial dilution, $100 \mu \mathrm{l}$ of each dilution was plated on Schaedler Selective Blood Agar plates supplemented with $5 \%$ bovine blood (Biolife Italiana, Milan, Italy) and incubated in $80 \%$ nitrogen $/ 10 \%$ hydrogen $/ 10 \%$ $\mathrm{CO} 2$ at $35^{\circ} \mathrm{C}$ to monitor $P$. gingivalis, $F$. nucleatum, Actinobacillus spp. and Peptostreptococcus micros. An additional $100 \mu \mathrm{l}$ was plated on Columbia agar containing $5 \%$ bovine blood (Biolife Italiana) in $5 \% \mathrm{CO}_{2}$ to monitor Gemella spp., Streptococcus spp., Leuconostoc spp., and Granulicatella spp. Microorganisms were identified by standard procedures (11) as well as the production of a set of metabolic enzymes (as tested with Rapid ID 32A and Rapid ID32 Strep) $(12,13)$. With regard to bacterial counts, the results were expressed in MCF, equivalent to $1.5 \times 108$ cells $/ \mathrm{ml}$.

- Statistical analysis

Single and crossed descriptive analyses were used to establish prevalence, and the $\chi^{2}$ test was used to establish the statistical significance of the differences in distributions (significance level: $P<0.05$ ). The data were analyzed using SPSS statistical software.

\section{Results}

Oral mucositis, according to WHO scores, involving nonkeratinized sites developed in 10 patients $(66.6 \%)$ 
Table 1. Patient characteristics.

\begin{tabular}{|c|c|c|c|c|}
\hline PATIENT & SEX & AGE & CHEMOTHERAPY & DIAGNOSIS \\
\hline 1 & M & 49 & YES & Lung cancer \\
\hline 2 & M & 56 & YES & Colon-rectum cancer \\
\hline 3 & $\mathrm{~F}$ & 32 & NO & Breast cancer \\
\hline 4 & M & 41 & $\mathrm{NO}$ & Colon-rectum cancer \\
\hline 5 & $\mathrm{~F}$ & 44 & $\mathrm{NO}$ & Breast cancer \\
\hline 6 & $\mathrm{~F}$ & 48 & $\mathrm{NO}$ & Lung cancer \\
\hline 7 & $\mathrm{~F}$ & 36 & YES & Colon-rectum cancer \\
\hline 8 & M & 43 & YES & Prostate cancer \\
\hline 9 & M & 59 & NO & Lung cancer \\
\hline 10 & $\mathrm{~F}$ & 52 & YES & Breast cancer \\
\hline 11 & M & 39 & YES & Prostate cancer \\
\hline 12 & M & 58 & YES & Colon-rectum cancer \\
\hline 13 & M & 45 & $\mathrm{NO}$ & Lung cancer \\
\hline 14 & $\mathrm{~F}$ & 56 & YES & Breast cancer \\
\hline 15 & $\mathrm{~F}$ & 38 & NO & Colon-rectum cancer \\
\hline 16 & M & 40 & $\mathrm{NO}$ & Colon-rectum cancer \\
\hline 17 & $\mathrm{~F}$ & 57 & YES & Breast cancer \\
\hline 18 & M & 43 & YES & Colon-rectum cancer \\
\hline 19 & M & 39 & YES & Prostate cancer \\
\hline 20 & M & 58 & $\mathrm{NO}$ & Lung cancer \\
\hline 21 & $\mathrm{~F}$ & 46 & NO & Breast cancer \\
\hline 22 & M & 57 & YES & Colon-rectum cancer \\
\hline 23 & $\mathrm{~F}$ & 55 & NO & Breast cancer \\
\hline 24 & $\mathrm{~F}$ & 47. & $\mathrm{NO}$ & Colon-rectum cancer \\
\hline 25 & $\mathrm{~F}$ & 41 & YES & Colon-rectum cancer \\
\hline 26 & M & 37 & $\mathrm{NO}$ & Lung cancer \\
\hline 27 & M & 58 & YES & Colon-rectum cancer \\
\hline 28 & $\mathrm{~F}$ & 52 & NO & Breast cancer \\
\hline 29 & M & 48 & $\mathrm{NO}$ & Colon-rectum cancer \\
\hline 30 & $\mathrm{~F}$ & 53 & YES & Colon-rectum cancer \\
\hline
\end{tabular}


in the test group: eight with grade 1 and two with grade 2. No ulcerations on the keratinized mucosa were scored. No mucositis developed in the control group. Table 2 shows 17 patients (57\%) who developed plaque that consisted predominantly of saprophytic Grampositive cocci (Streptococcus spp., Leuconostoc spp., Granulicatella spp. and Gemella spp.). Nine of these patients underwent chemotherapy (53\%). The other 13

Table 2. Mean numbers of bacteria in the study population.

\begin{tabular}{|c|c|c|c|c|c|c|}
\hline \multirow{2}{*}{ PATIENT } & \multirow{2}{*}{ SEX } & \multirow{2}{*}{ BACTERIA } & \multirow[t]{2}{*}{ CHEMOTHERAPY } & \multicolumn{3}{|c|}{$\begin{array}{c}\mathrm{N}\left(\mathrm{McF}=1.5 \times 10^{8}\right. \\
\text { cells } / \mathrm{ml})\end{array}$} \\
\hline & & & & to & t1 & t2 \\
\hline 1 & M & Granulicatella spp. & YES & 0.5 & 0.5 & 0.45 \\
\hline 2 & M & Fusobacterium Nucleatum & YES & 0.3 & 0.3 & 0.3 \\
\hline 3 & $\mathrm{~F}$ & Gemella spp. & NO & 0.5 & 0.5 & 0.5 \\
\hline 4 & M & Peptostreptococcus micros & NO & 0.4 & 0.4 & 0.45 \\
\hline 5 & $\mathrm{~F}$ & Actinobacillus spp. & NO & 0.3 & 0.3 & 0.3 \\
\hline 6 & $\mathrm{~F}$ & Streptococcus spp & NO & 0.5 & 0.5 & 0.5 \\
\hline 7 & $\mathrm{~F}$ & Granulicatella spp. & YES & 0.5 & 0.5 & 0.5 \\
\hline 8 & M & Gemella spp. & YES & 0.5 & 0.5 & 0.55 \\
\hline 9 & M & Leuconostoc spp. & NO & 1.5 & 1.5 & 1.5 \\
\hline 10 & $\mathrm{~F}$ & Fusobacterium Nucleatum & YES & 0.3 & 0.3 & 0.3 \\
\hline 11 & $\mathrm{M}$ & Streptococcus spp & YES & 0.5 & 0.5 & 0.5 \\
\hline 12 & M & Peptostreptococcus micros & YES & 0.4 & 0.4 & 0.4 \\
\hline 13 & M & Porphyromonas gingivalis & NO & 0.3 & 0.3 & 0.3 \\
\hline 14 & $\mathrm{~F}$ & Actinobacillus spp. & YES & 0.3 & 0.3 & 0.3 \\
\hline 15 & $\mathrm{~F}$ & Streptococcus spp & NO & 0.5 & 0.5 & 0.5 \\
\hline 16 & M & Peptostreptococcus micros & NO & 0.4 & 0.4 & 0.4 \\
\hline 17 & $\mathrm{~F}$ & Leuconostoc spp. & YES & 1.5 & 1.5 & 1.5 \\
\hline 18 & M & Fusobacterium Nucleatum & YES & 0.3 & 0.3 & 0.3 \\
\hline 19 & M & Streptococcus spp & YES & 0.5 & 0.5 & 0.5 \\
\hline 20 & M & Streptococcus spp & NO & 0.5 & 0.5 & 0.5 \\
\hline 21 & $\mathrm{~F}$ & Porphyromonas gingivalis & NO & 0.3 & 0.3 & 0.3 \\
\hline 22 & M & Gemella spp. & YES & 0.5 & 0.5 & 0.5 \\
\hline 23 & $\mathrm{~F}$ & Fusobacterium Nucleatum & NO & 0.3 & 0.3 & 0.3 \\
\hline 24 & $\mathrm{~F}$ & Gemella spp. & NO & 0.5 & 0.5 & 0.5 \\
\hline 25 & $\mathrm{~F}$ & Granulicatella spp. & YES & 0.5 & 0.5 & 0.5 \\
\hline 26 & M & Leuconostoc spp. & NO & 1.5 & 1.5 & 1.5 \\
\hline 27 & M & Peptostreptococcus micros & YES & 0.4 & 0.4 & 0.4 \\
\hline 28 & $\mathrm{~F}$ & Leuconostoc spp. & NO & 1.5 & 1.5 & 1.5 \\
\hline 29 & M & Porphyromonas gingivalis & NO & 0.3 & 0.3 & 0.3 \\
\hline 30 & $\mathrm{~F}$ & Streptococcus spp & YES & 0.5 & 0.5 & 0.5 \\
\hline
\end{tabular}


patients $(43 \%)$ developed periodontal pathogens ( $F$. nucleatum, $P$. gingivalis, Actinobacillus spp. and Pep. micros). Six of these patients (46\%) were undergoing chemotherapy. No $P$. gingivalis appeared in the test group. Actinobacillus spp. were the least frequently found periodontal pathogen in the test group $(6.6 \%)$, while $F$. nucleatum was the most frequently found
$(20 \%)$. No significant differences were found in bacterial changes between $\mathrm{t} 0, \mathrm{t} 1$, and $\mathrm{t} 2$ in the test group (Fig. 1). In the control group, the bacterial count remained unchanged during the observation period (Fig. 2). At $\mathrm{t} 0, \mathrm{t} 1$ and $\mathrm{t} 2$, differences in qualitative and quantitative variations between the two groups were not significant (Fig. 3).

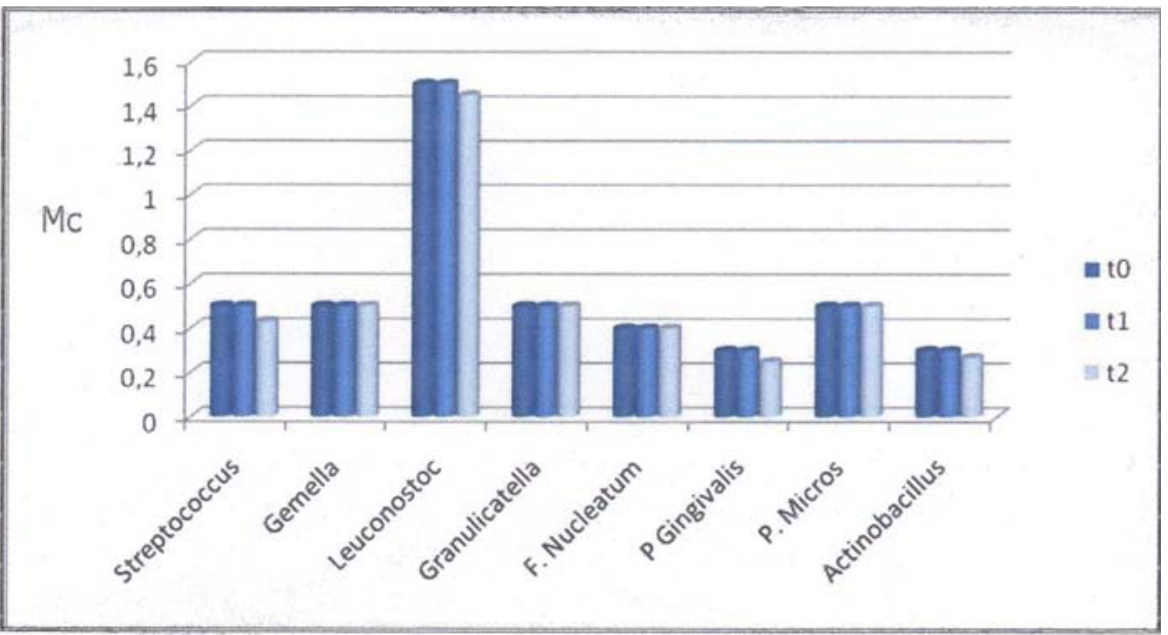

Fig. 1. Mean numbers of bacteria in the samples in the test group.

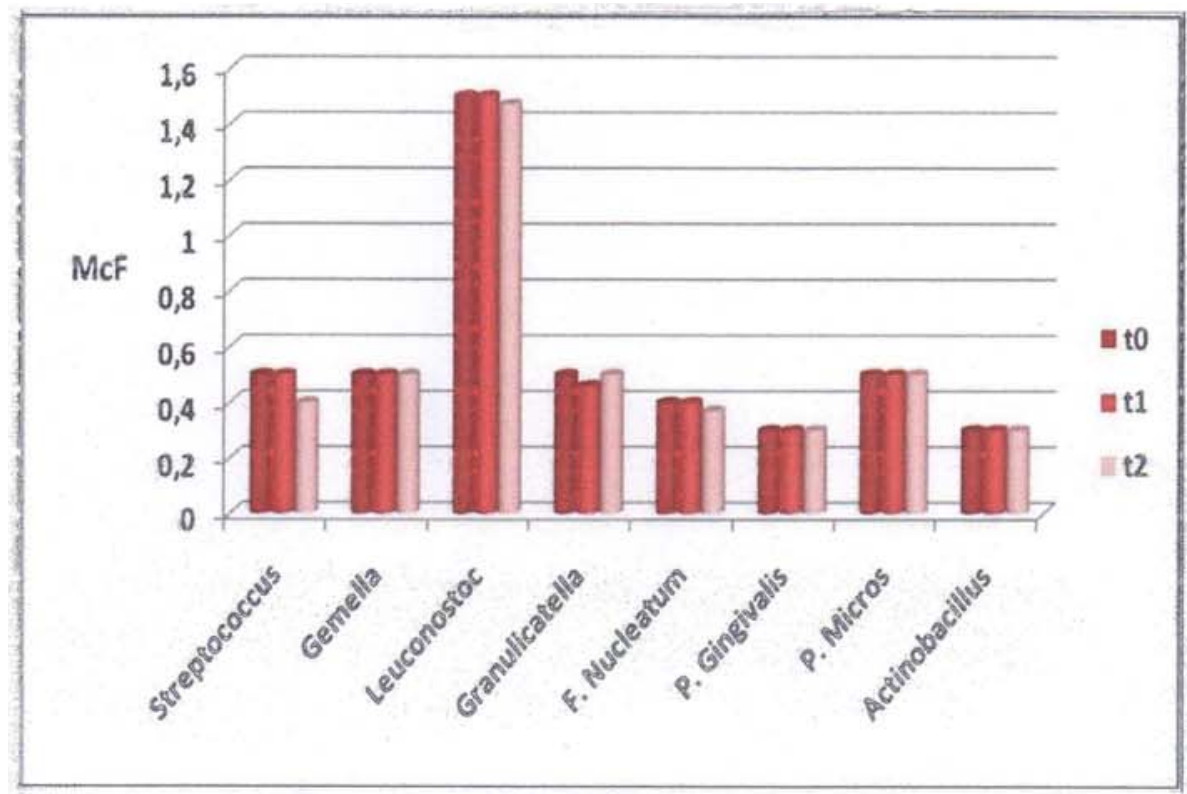

Fig. 2. Mean numbers of bacteria in the samples in the control group. 


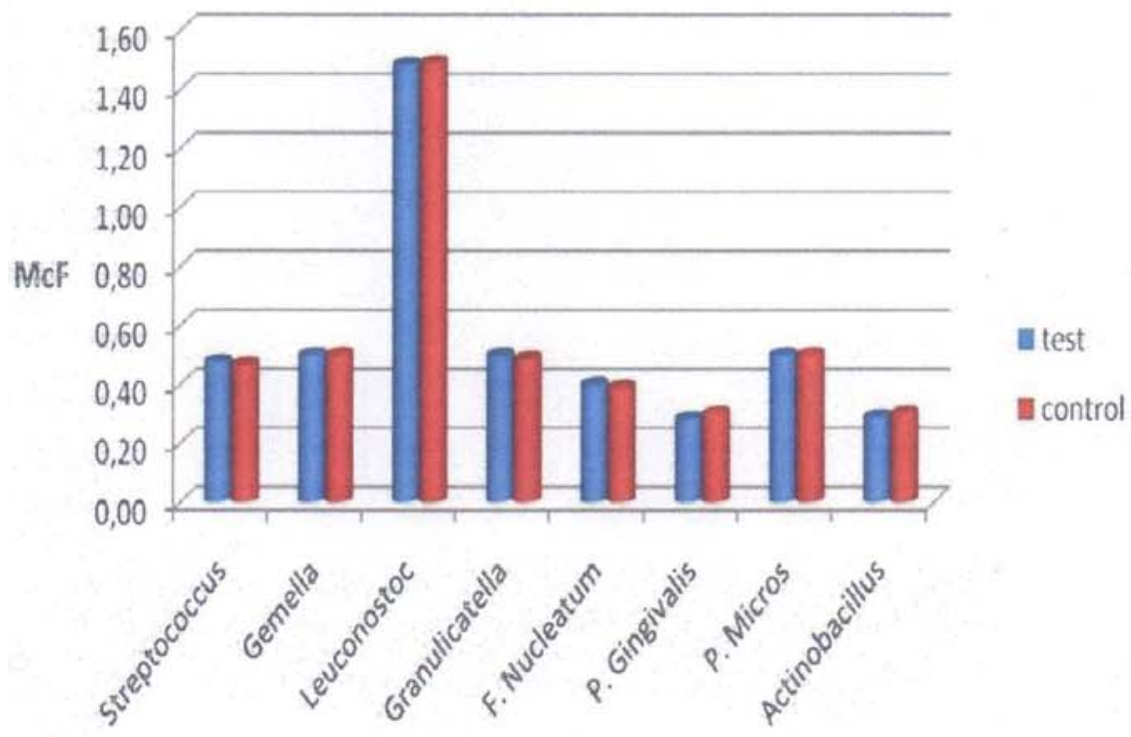

Fig. 3. Cross-sectional analysis of mean bacterial counts between the two groups.

\section{Discussion}

Supragingival plaque is influenced by saliva and gingival fluid and allows the growth of aerobic and anaerobic organisms (14), ultimately leading to complex microflora dominated by Gram-positive bacteria, particularly streptococci. This flora can be representative of the oral flora during chemotherapy (15), as found in our present study. The microflora undergo modifications during the day, particularly due to eating, and for this reason, all sampling was done $2 \mathrm{~h}$ after breakfast. The standardization of sampling allowed us to minimize variations related to this parameter.

The microorganisms monitored in this study were saprophytic species of the oral cavity (Streptococcus spp., Leuconostoc spp., Granulicatella spp. and Gemella spp.) and species associated with periodontal pathology (P. gingivalis, Actinobacillus spp., Peptostreptococcus spp. and F. nucleatum). These periodontal pathogens are known for their association with periodontal diseases in immunosuppressed individuals (15-17). In our pilot study $F$. nucleatum was the most frequently found periodontal pathogen in dental plaque of patients undergoing chemotherapy. However, none of our patients showed any sign of serious periodontal pathology and periodontal probing, was not part of the standard of care during our study. Therefore, it was not possible to make such conclusions from this study.

The dental plaque flora are constantly influenced by external sources, such as nosocomial infections, gastroesophageal reflux, and systemic and oral treatments. Topical, oral and parenteral antimicrobials before and during cancer chemotherapy should alter the quantitative and qualitative oral microflora profile (18).
For this reason, the use of antimicrobial agents was an exclusion criterion for our study. Children differ from adults in their oral microflora, and in their response to chemotherapeutic regimens. Most of the oral bacterial changes noted in pediatric studies involved Grampositive streptococci and staphylococci, whereas in studies of adults, most changes involved Gram-negative organisms such as Enterobacteriaceae and Pseudomonas spp. (15).

There is no consensus regarding qualitative and quantitative changes in oral microflora during cancer chemotherapy, or a clear pattern or association between mucositis and changes in oral microflora (2). Previous studies have differed in many important aspects, including patient populations and presence of a control group, chemotherapeutic regimens, use of antimicrobials during chemotherapy, sample sites and number of samples collected, collection times and methods, microorganisms cultured, and the scoring method for mucositis. Thus, it is difficult to compare our results to those of other studies. Our results showed that, although there was a reduction in the number of oral bacteria in $5 \%$ of patients in the test group, in the remaining $95 \%$, there was no significant change in the number of bacteria analyzed from to to $\mathrm{t} 2$. Similarly, the test group showed no change in bacterial microflora between beginning chemotherapy and at the end of treatment.

The cross-sectional analysis showed no significant differences between the test and control groups. In slightly more than half of the patients $(57 \%)$, the oral microflora consisted mainly of Gram-positive cocci (saprophytic species of the oral cavity), while the 
remaining $43 \%$ of the patients had bacterial flora that also had periodontal-pathogenic species. The only difference between the two groups was the incidence of mucositis, which was present only in the test group. These results suggest that bacterial pathogenicity is due less to changes in the intrinsic micro-habitat of the oral cavity, and more to a decrease in the efficiency of the immune response (19). However in this study, the relationship between leukocyte counts and quantitative oral microflora changes was not determined.

The combination of mucositis and granulocytopenia increases the risk of systemic infection resulting from invasion of oral microflora into the bloodstream. However, although it is postulated that some oral bacteria may exacerbate mucositis, it cannot be determined from the results that the presence of local or systemic bacterial infection correlates with the onset and severity of mucositis (20). P. gingivalis was consistently associated with oral ulcerations in a study of hematopoietic stem cell transplant patients and had a positive predictive value (8). $P$. gingivalis possesses several virulence factors such as fimbriae that enable the bacterium to at)ach to and invade epithelial cells (21), and a lipopolysaccharide capsule that is highly antigenic and can induce the production of proinflammatory cytokines (22). These virulence factors might prolong or intensify oral ulcerations and could explain the role of $P$. gingivalis in mucositis. Nevertheless, in our study, no patient undergoing chemotherapy had $P$. gingivalis in the plaque samples.

\section{Conclusion}

Within the limitations of the small sample size of our pilot study, it can be concluded that no changes occur in microflora in dental plaque in cancer patients within 7 days from the first course of chemotherapy. No correlations between oral mucositis and specific microorganisms were assessed. More patients are required to increase the reliability of the results, and more detailed studies are necessary to understand the relationship between chemotherapy, alterations in the nature and magnitude of the oral microflora, and the presence of mucositis. Better characterization of changes in oral microflora would be obtained using molecular biological techniques. This would help our understanding of the potential role of oral microflora in the development and exacerbation of oral mucositis. Data from such work could be directed toward developing and testing selective antimicrobial therapies for the prevention and management of mucositis during cancer chemotherapy.

\section{References}

1. Paster BJ, Boches SK, Galvin JL, Ericson RE, Lau CN, Levanos $\mathrm{VA}$, et al. Bacterial diversity in human subgingival plaque. J Bacteriol. 2001;183:3770-83.

2. Napenas JJ, Brennan MT, Bahrani-Mougeot FK, Fox PC, Lockhart PB. Relationship between mucositis and changes in oral microflora during cancer chemotherapy. Oral Surg Oral Med Oral Pathol Oral Radiol Endod. 2007;103:48-59.

3. He J, Huang W, Pan Z, Cui H, Qi G, Zhou X, et al. Quantitative analysis of microbiota in saliva, supragingival, and subgingival plaque of Chinese adults with chronic periodontitis. Clin Oral Investig. 2012;16:1579-88.

4. Slots J, Rams TE. New views on periodontal microbiota in special patient categories. J Clin Periodontol. 1991;18:411-20.

5. Paju S, Pussinen PJ, Suominen-Taipale L, Hyvönen M, Knuuttila M, Könönen E. Detection of multiple pathogenic species in saliva is associated with periodontal infection in adults. J Clin Microbiol. 2009;47:235-8.

6. Feller L, Essop R, Wood NH, Khammissa RA, Chikte UM, Meyerov R, et al. Chemotherapy- and radiotherapy-induced oral mucositis: pathobiology, epidemiology and management. SADJ. 2010;65:372-4.

7. Raber-Durlacher JE, Weijl NI, Abu Saris M, de Koning B, Zwinderman AH, Osanto S. Oral mucositis in patients treated with chemotherapy for solid tumors: a retrospective analysis of 150 cases. Support Care Cancer. 2000;8:366-71.

8. Laheij AM, de Soet JJ, von dem Borne PA, Kuijper EJ, Kraneveld EA, van Loveren C, et al. Oral bacteria and yeasts in relationship to oral ulcerations in hematopoietic stem cell transplant recipients. Support Care Cancer. 2012;20:3231-40.

9. Clarkson JE, Worthington HV, Furness S, McCabe M, Khalid $\mathrm{T}$, Meyer S. Interventions for treating oral mucositis for patients with cancer receiving treatment. Cochrane Database Syst Rev. 2010;8:CD001973.

10. Freitas AC, Campos L, Brandão TB, Cristófaro M, Eduardo FP, Luiz AC, et al. Chemotherapy-Induced Oral Mucositis: Effect of LED and Laser Phototherapy Treatment Protocols. Photomed Laser Surg. 2014;32:81-7.

11. Murray PR, Traynor P, Hopson D. Critical assessment of blood culturetechniques: analysis of recovery of obligate and facultative anaerobes, strict aerobic bacteria, and fungi in aerobic and anaerobic blood culture bottles. J Clin Microbiol. 1992;30:1462-8.

12. Pattyn SR, Ieven M, Buffet L. Comparative evaluation of the Rapid ID 32A kit system, miniaturized standard procedure and a rapid fermentation procedure for the identification of anaerobic bacteria. Acta Clin Belg. 1993;48:81-5.

13. Freney J, Bland S, Etienne J, Desmonceaux M, Boeufgras JM, Fleurette J. Description and evaluation of the semiautomated 4-hour rapid ID 32 Strep method for identification of streptococci and members of related genera. J Clin Microbiol. 1992;30:2657-61.

14. Fujinaka H, Takeshita T, Sato H, Yamamoto T, Nakamura J, Hase $\mathrm{T}$, et al. Relationship of periodontal clinical parameters with bacterial composition in human dental plaque. Arch Microbiol. 2013;195:37183.

15. Sixou JL, De Medeiros-Batista O, Gandemer V, BonnaureMallet M. The effect of chemotherapy on the supragingival plaque of pediatric cancer patients. Oral Oncol. 1998;34:476-83.

16. Kostic AD, Chun E, Robertson L, Glickman JN, Gallini CA, Michaud M, et al. Fusobacterium nucleatum potentiates intestinal tumorigenesis and modulates the tumor-immune microenvironment. Cell Host Microbe. 2013;14:207-15.

17. Katz J, Onate MD, Pauley KM, Bhattacharyya I, Cha S. Presence of Porphyromonas gingivalis in gingival squamous cell carcinoma. Int J Oral Sci. 2011;3:209-15. 
18. Lanzós I, Herrera D, Santos S, O’Connor A, Peña C, Lanzós E, et al. Microbiological effects of an antiseptic mouthrinse in irradiated cancer patients. Med Oral Patol Oral Cir Bucal. 2011;16:e1036-42.

19. Parisi E, Glick M. Immune suppression and considerations for dental care. Dent Clin North Am. 2003;47:709-31.

20. Vanhoecke B, De Ryck T, Stringer A, Van de Wiele T, Keefe D. Microbiota and their role in the pathogenesis of oral mucositis. Oral Dis. 2015;21:17-30.

21. Amano A. Bacterial adhesins to host components in periodontitis. Periodontol. 2000. 2010;52:12-37.

22. Vernal R, León R, Silva A, Winkelhoff AJ, Garcia-Sanz JA, Sanz M. Differential cytokine expression by human dendritic cells in response to different Porphyromonas gingivalis capsular serotypes. J Clin Periodontol. 2009;36:823-9.

\section{Conflict of Interest}

The authors declare that they have no conflict of interest. 